\title{
Topography-Guided Trans-Epithelial No-Touch Photorefractive Keratectomy for High Irregular Astigmatism After Penetrating Keratoplasty: A Prospective 12-Months Follow-Up
}

\section{Leopoldo Spadea (iD) \\ Giacomo Visioli (iD \\ Davide Mastromarino \\ Shehani Alexander \\ Santino Pistella}

Eye Clinic, Policlinico Umberto I, "Sapienza" University of Rome, Rome, Italy
Correspondence: Leopoldo Spadea Head Eye Clinic, Policlinico Umberto I, "Sapienza" University of Rome, Via Benozzo Gozzoli 34, Rome, 00I42, Italy Tel +3906 5193220

Fax +390688657818

Email leopoldo.spadea@uniromal.it
Purpose: To describe the efficacy and safety of topography-guided trans-epithelial no-touch photorefractive keratectomy (PRK) for the correction of highly irregular astigmatism after penetrating keratoplasty (PK).

Patients and Methods: A prospective study was conducted on 12 eyes of 12 patients affected by highly irregular astigmatism after PK for keratoconus. Each patient underwent a single-step topography-guided trans-epithelial ablation $\left(\mathrm{CIPTA}^{\circledR} 2\right.$ software, iVis Technologies). Corneal topography data as well as uncorrected (UDVA) and corrected distance visual acuity (CDVA) and spherical equivalent (SEQ) were collected preoperatively (T0) and at 1 (T1), 3 (T2) and 12 (T3) months after surgery.

Results: Mean UDVA and CDVA significantly improved, respectively, from $1.22 \pm 0.17$ and $0.18 \pm 0.03 \operatorname{LogMAR}$ at $\mathrm{T} 0$ to $0.63 \pm 0.17(\mathrm{CI} 95 \%, \mathrm{P}<0.001)$ and $0.04 \pm 0.03 \log M A R$ at $\mathrm{T} 3$ (CI $95 \%, \mathrm{P}<0.001)$. Mean SEQ significantly decreased from $-3.75 \pm 1.32$ to $-1.60 \pm 1.32 \mathrm{D}$ (CI $95 \%, \mathrm{P}<0.02$ ). Mean subjective refractive astigmatism (SRAST) and mean keratometry astigmatism (SimK) significantly decreased, respectively, from $7.83 \pm 0.98$ and $8.10 \pm 1.48 \mathrm{D}$ to $2.83 \pm 0.98$ and $5.29 \pm 1.48 \mathrm{D}$ (CI 95\%, $\mathrm{P}<0.001$ ). Corneal Morphological Irregularity index (CMI) significantly decreased from $62.76 \pm 7.26 \mu \mathrm{m}$ to $23.24 \pm 7.26 \mu \mathrm{m}$ (CI 95\%, P<0.001). Apart from a single episode of graft rejection 5 days after ablation, successfully reverted with topical steroids, no other complications were noted. A mild corneal haze was observed in two eyes (16.7\%) at 3 months post-PRK, and no regression was observed at 12 months.

Conclusion: Our study demonstrates the safety and long-term effectiveness of a transepithelial topography-guided ablation in the treatment of post-PK highly irregular astigmatism.

Keywords: PRK, corneal aberrations, keratoconus, refraction, corneal transplant

\section{Introduction}

Significant ocular aberrations due to corneal surface irregularity secondary to penetrating keratoplasty (PK) may have a significant impact and pose a major barrier in the successful visual rehabilitation of patients. The main complications in patients who undergo PK are postoperative irregular astigmatism, which is reported to impair visual rehabilitation in $8-20 \%$ of patients. ${ }^{1,2}$ Many factors may lead to an increased risk of post-PK astigmatism: preoperative keratoconus (KC), corneal thickness, and donor-recipient disparity, eccentric trephination of the host, 
oversized grafts, and the suture technique applied. ${ }^{3}$ Disparity between donor button and recipient bed, between the shapes of the wound margins of the host and the recipient, malposition of donor and recipient corneas is also associated with high-order astigmatism and aberrations. $^{4}$

Spectacles are often insufficient to correct residual refractive defects since the refractive error is not truly spherocylindrical. Rigid gas-permeable or scleral contact lenses (CL) may represent an effective treatment, ${ }^{5-7}$ even though complications can frequently arise, such as chronic allergic reactions, peripheral neovascularization with increased risk of graft rejection, ulcerative or infective keratitis for malpractice, intolerance to the devices and poor patient compliance. ${ }^{8,9}$ Selective suture removal or adjustments, relaxing incisions, wedge resection, or astigmatic keratotomy, although helpful, cannot usually completely correct the refractive defects, resulting in poor predictable outcomes or irregular astigmatism. ${ }^{3,10}$

Refractive laser treatments, including laser in-situ keratomileusis (LASIK) and photorefractive keratectomy (PRK), have been widely and successfully performed in the treatment of post-PK residual refractive defects. ${ }^{11-13}$ In particular, trans-epithelial laser refractive surgery has shown its better efficacy, safety, and predictability for the treatment of lower- and higher-order aberrations, even if long-term outcomes after PK for keratoconus have not been strongly confirmed. ${ }^{11,14-16}$

Moreover, topography-guided excimer laser treatment has been shown to be a potentially effective technique due to its ability to analyze and localize corneal irregularities that have to be reshaped. ${ }^{14}$

The results of a topography-guided trans-epithelial notouch PRK for high residual astigmatism occurring after PK in a cohort of 12 patients with a follow-up of 12 months are presented.

\section{Patients and Methods Setting and Study Design}

The present study has been performed in accordance with the principles stated in the Declaration of Helsinki and obtained ethical approval from the local Institutional Review Board (IRB) of the "Sapienza" University of Rome, Umberto I Hospital. Informed consent was obtained from all patients before enrollment.

A prospective study in a referral center for a corneal transplant which included consecutive adult patients with
post-PK highly irregular astigmatism not satisfied with spectacles or CL correction was conducted. Patients enrolled from August to December 2019 underwent trans-epithelial topography-guided ablation of the transplanted eye with a total follow-up of 12 months. Inclusion criteria were as follows: (1) single PK to correct keratoconus performed by the same expert surgeon (LS) at least 3 years before enrollment with no previous other surgeries (ie corneal collagen crosslinking), (2) keratoplasty sutures removed for at least 1 year resulting in high irregular astigmatism with corneal morphological irregularity index $(\mathrm{CMI})>40 \mu \mathrm{m},{ }^{16}$ (3) intolerance to spectacles and/or CL, (4) high subjective visual aberrations, (5) age between 18 and 70 years, (6) written informed consent signed. The CMI measures the morphological irregularities, above the second order, of the corneal surfaces, within a circular domain of a predefined diameter equal to diameter, usually in the central $6 \mathrm{~mm}$. CMI is intrinsically related to the quality of vision of the patient: the higher the value, the worse the quality of vision. The CMI is measured by Precisio ${ }^{\circledR} 2$ tomographer (iVis Technologies, Taranto, Italy) and it is defined as the sum of the absolute values of the maximum and the minimum difference between the examined corneal shape and its best fit toric surface determined within the diameter domain.

We excluded patients affected by cataract, glaucoma, amblyopia, uveitis and retinal diseases, active ocular pathologies involving the cornea and active systemic diseases.

\section{Data Collection}

During the study period for each enrolled patient, we collected anamnestic and preoperative data (T0) and postPRK data at 1 month (T1), 3 months (T2), and 12 months (T3). From T0 to T3, ophthalmologic data included uncorrected (UDVA) and corrected distance visual acuity (CDVA) expressed in logarithm of the minimum angle of resolution (LogMAR), subjective refractive astigmatism (SRAST), and keratometric astigmatism at $3 \mathrm{~mm}$ area (or simulated keratometry, SimK), spherical equivalent (SEQ), minimum corneal thickness (MCT), corneal morphological irregularity index (CMI), applanation tonometry, and anterior segment examination. Pre-operative evaluation (T0) also included cycloplegia refraction, posterior segment examination, and laser planning, performed with a blue laser high-resolution corneal tomography (Precisio ${ }^{\circledR} 2$, iVIS Technologies, Taranto, Italy) and a dynamic pupillometry (pMetrics, iVIS Technologies, Taranto, Italy). 


\section{Surgical Procedure}

Twelve eyes of 12 patients, 7 females and 5 males, with a mean age of 40.2 years (range 24 to 54 years old), underwent one-step topography-guided trans-epithelial notouch surgery to correct high irregular astigmatism after a mean of $119.2 \pm 67.2$ months (range 39 to 271) from PK for keratoconus. The customization of the laser treatment was based on morphological and refractive data generated by the tomographer; spherical error collected by visual acuity examination; target refractive zone and ablation zone defined by the projection of an ideal pupil, identified by dynamic pupillometry, onto the ideal corneal surface.

A customized trans-epithelial treatment was planned to take care of the refractive contribution of the epithelium which, due to its smoothing effect, had an abnormal thickness distribution. The customized treatment plan was executed by means of the "Corneal Interactive Programmed Topographic Ablation" software $\left(\mathrm{CIPTA}^{\circledR} 2\right.$, iVIS Technologies, Taranto, Italy). This software determines the volume of ablation as the intersection between the anterior shape detected by Precisio ${ }^{\circledR} 2$ and the ideal shape determined taking care of the total corneal astigmatism and of the high order of aberrations, by means of a ray tracing process. The refractive correction therefore takes care of the total corneal astigmatism, the corneal aberrations above the second order and eventually the subjective spherical error.

Two drops of oxybuprocaine were applied $5 \mathrm{~min}$ before surgery and after the insertion of the eye speculum. Following cyclotorsional measurement and pupil eyetracker registration, the treatment was performed with a $0.6 \mathrm{~mm}$ dual-flying-spot $1 \mathrm{KHz}$ excimer laser (iRES ${ }^{\circledR}$, iVIS Technologies, Taranto, Italy) using the one-step custom trans-epithelial "no-touch" $\left(\mathrm{cTEN}^{\circledR}\right.$, iVIS Technologies, Taranto, Italy) ablation technique. Mitomycin $\mathrm{C}$ was not applied during the procedure in order to exclude confounding factors. The mean targeted optical zone diameter was $2.89 \pm 0.63 \mathrm{~mm}$. The maximum depth ablation was $115.3 \pm 13.3 \mu \mathrm{m}$ (range $73-128 \mu \mathrm{m}$ ), assuming the target residual pachymetry of $467.2 \pm 35.2$ $\mu \mathrm{m}$. The mean targeted residual cylinder was 0 diopters (D).

At the end of the laser procedure, a bandage soft contact lens (PureVision 2, Bausch \& Lomb, Rochester, USA) was applied and removed after 3 days. Postoperative treatment included $15 \mathrm{mg}$ of oral prednisone per day and tapered for the first month to prevent graft rejection, ofloxacin eye drops 3 times a day, and artificial tears 6 times a day throughout the follow-up.

After CL removal and epithelial resurfacing, patients were prescribed topical dexamethasone $1.5 \mathrm{mg} / \mathrm{mL} 3$ times a day for 1 month, followed by $0.1 \%$ fluorometholone eye drops 3 times and tapered to one drop each month for the next 3 months.

\section{Statistical Analysis}

An assessment of the normal distribution of data to set the right comparison method for statistical analysis was verified using the Shapiro-Wilk test. Descriptive statistics of continuous ophthalmologic data were reported as mean, range, and standard deviation. To test for the statistical significance of the differences in the continuous values between $\mathrm{T} 0$ and other follow-up times, a linear panel regression analysis was run and marginal effects, as well as confidence intervals $(95 \%)$, were obtained for each dependent variable.

To evaluate if subjective and keratometric astigmatism could have different improvements between T0 and T3, a correlation between SRAST and Ksim was investigated by a univariate linear regression. $P$ values below 0.05 were considered statistically significant $(\alpha=5 \%)$. Data distribution and statistical analysis were performed using STATA, v. 14.0 (StataCorp, TX, USA).

\section{Results}

A sample corneal topography with the preoperative and the post-PRK axial map of a 39 years old woman with post-PK highly irregular astigmatism, included in the cohort, is shown in Figure 1.

\section{Efficacy}

Descriptive statistics with mean values and standard deviation at enrollment (T0), at 1 month (T1), at 3 months (T2), and 12 months (T3) are summarized in Table 1. An improvement by 2 or more lines of UDVA LogMAR between T0 and T3 was observed in $11(92 \%)$, by 4 or more lines in 9 (75\%), by 6 or more in $5(42 \%)$ of 12 eyes, with a mean improvement of $5.67 \pm 2.93$ lines. An improvement by 1 or more lines of CDVA LogMAR between T0 and T3 was observed in $12(100 \%)$ of 12 eyes, with a mean improvement of $1.42 \pm 0.67$ lines.

In the linear panel regression analysis, the estimated value of UDVA obtained as marginal effect improved from 1.22 $\pm 0.17 \mathrm{LogMAR}$ (Snellen equivalent $\sim 6 / 50$ ) preoperatively (T0) to $0.63 \pm 0.17 \operatorname{LogMAR}$ (Snellen equivalent $\sim 12 / 50$ ) at 
A

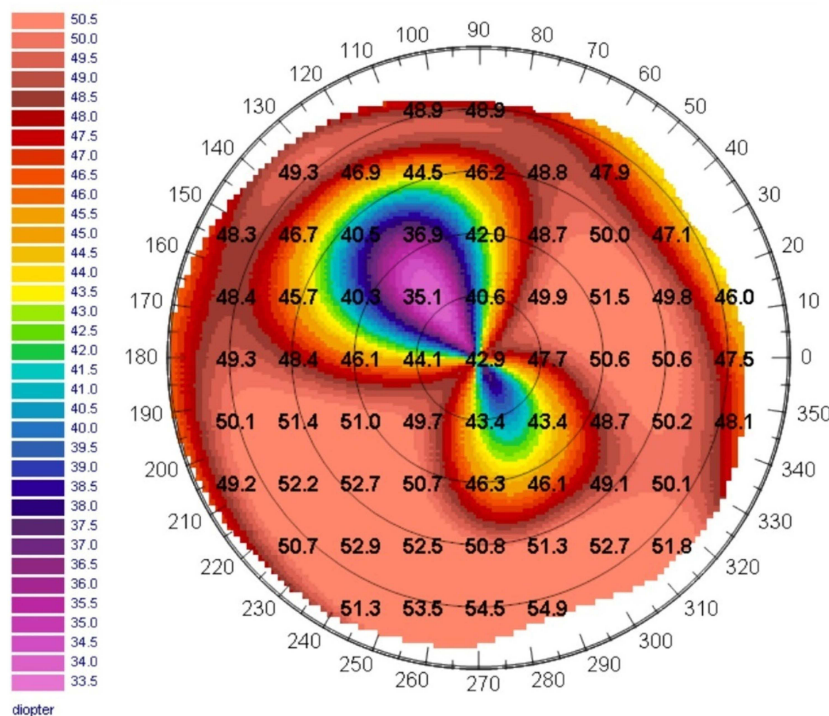

C
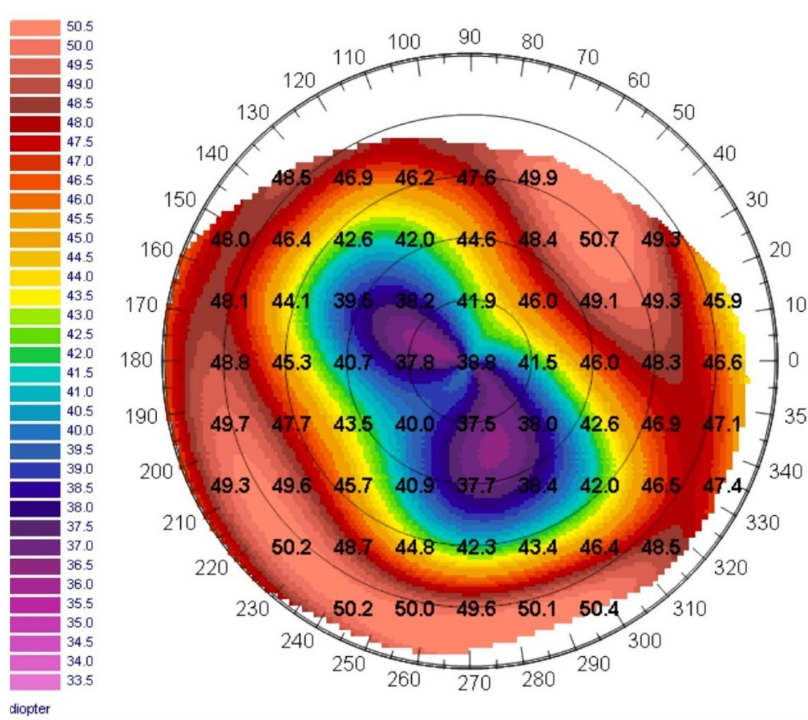
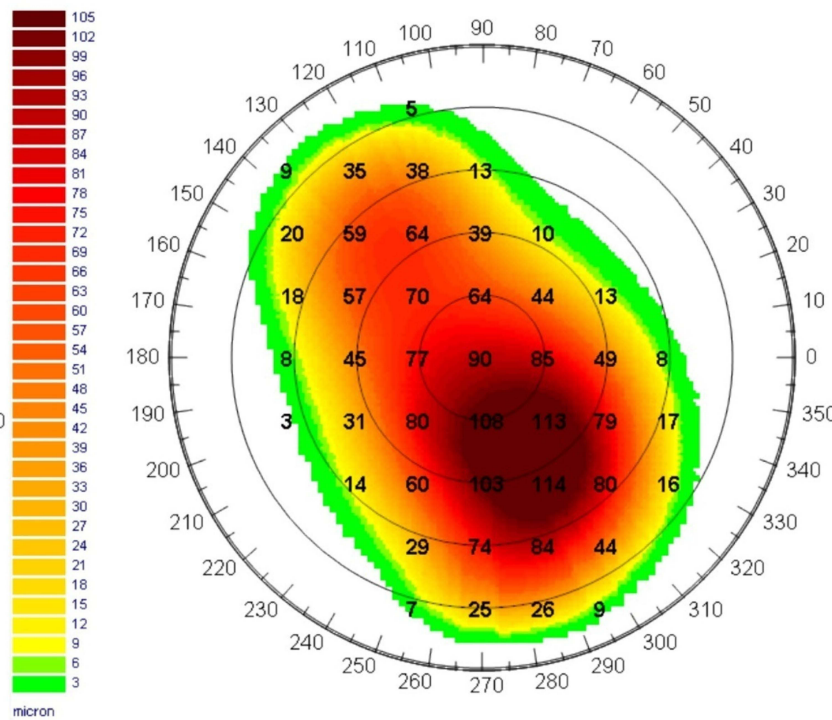

Figure I Sample corneal topography with preoperative and post-PRK axial map of a 39 years old woman included in the cohort. (A) Preoperative (T0) corneal axial map with a post-PK high irregular astigmatism. Preoperative CDVA was 0.18 LogMAR, spherical equivalent (SEQ) was -7D, refractive astigmatism (SRAST) was IID and keratometric astigmatism (SimK) was I2.ID. (B) Expected ablation depth map with planned customized trans-epithelial PRK treatment: the calculated ablation in the optical zone is $121 \mu \mathrm{m}$. (C) Postoperative corneal axial map at 12 months (T3) after PRK with reduction of topographic astigmatism and regularization of corneal morphology especially in the central area. (D) Achieved ablation depth map at 12 months (T3) after PRK. Postoperative CDVA was 0.05 LogMar, spherical equivalent (SEQ) was -ID, refractive astigmatism (SRAST) was 6D and keratometric astigmatism (SimK) was 7.75D. Compared to expected ablation depth map, no substantial differences are highlighted. This is a sign that the ablation was conducted as planned.

12 months follow-up (T3) $(P<0.0001)$. The preoperative CDVA improved from $0.18 \pm 0.03 \operatorname{LogMAR}$ (Snellen equivalent $\sim 33 / 50$ ) at $\mathrm{T} 0$ to $0.04 \pm 0.03 \operatorname{LogMAR}$ (Snellen equivalent $\sim 45 / 50)$ at T3 $(P<0.0001)$. The SEQ improved from -3.75 $\pm 1.32 \mathrm{D}$ at $\mathrm{T} 0$ to $-1.60 \pm 1.32 \mathrm{D}$ at $\mathrm{T} 3(P<0.02)$. The SRAST improved from $7.83 \pm 0.98 \mathrm{D}$ at $\mathrm{T} 0$ to $2.83 \pm 0.98 \mathrm{D}$ at $\mathrm{T} 3$ $(P<0.0001)$. Keratometric astigmatism (SimK) improved from $8.10 \pm 1.48 \mathrm{D}$ at $\mathrm{T} 0$ to $5.29 \pm 1.48 \mathrm{D}$ at $\mathrm{T} 3(P<0.0001)$.
Minimum corneal thickness (MCT) was reduced from $548.92 \pm 18.18 \mu \mathrm{m}$ at $\mathrm{T} 0$ to $477.55 \pm 18.18 \mu \mathrm{m}$ at $\mathrm{T} 3$ $(P<0.0001)$. Corneal morphological irregularity index (CMI) decreased from $62.76 \pm 7.26 \mu \mathrm{m}$ at $\mathrm{T} 0$ to $23.24 \pm 7.26 \mu \mathrm{m}$ at $\mathrm{T} 3$ (CI 95\%, $\mathrm{P}<0.001$ ). The marginal effects of the evaluated parameters from the regression analysis are summarized in Figure 2. Overall, the differences between $\mathrm{T} 0$ and the other follow-ups are statistically significant, except for the effect on 
Table I Summary of the Mean Changes During the Follow-Up

\begin{tabular}{|c|c|c|c|c|}
\hline & T0 (Mean \pm SD) & TI (Mean \pm SD) & T2 (Mean \pm SD) & T3 (Mean \pm SD) \\
\hline UDVA (LogMAR) & $1.22 \pm 0.26$ & $0.62 \pm 0.33$ & $0.62 \pm 0.29$ & $0.63 \pm 0.32$ \\
\hline CDVA (LogMAR) & $0.18 \pm 0.08$ & $0.05 \pm 0.05$ & $0.04 \pm 0.03$ & $0.04 \pm 0.03$ \\
\hline SEQ (D) & $-3.75 \pm 3.72$ & $-|.83 \pm 1.6|$ & $-1.61 \pm 1.85$ & $-|.60 \pm| .4 \mid$ \\
\hline SRAST (D) & $7.83 \pm 2.81$ & $2.46 \pm 1.08$ & $2.94 \pm 1.10$ & $2.83 \pm 1.35$ \\
\hline SimK (D) & $8.10 \pm 3.28$ & $4.96 \pm 2.23$ & $5.14 \pm 2.5 \mid$ & $5.29 \pm 2.31$ \\
\hline CMI $(\mu \mathrm{m})$ & $62.76 \pm 21.41$ & $21.06 \pm 8.54$ & $21.30 \pm 7.23$ & $23.24 \pm 8.72$ \\
\hline MCT $(\mu \mathrm{m})$ & $548.92 \pm 34.08$ & $472.25 \pm 32.27$ & $475.63 \pm 27.85$ & $477.55 \pm 33.89$ \\
\hline
\end{tabular}

Abbreviations: UDVA, uncorrected distance visual acuity; CDVA, corrected distance visual acuity; SEQ, spherical equivalent; SRAST, subjective refractive astigmatism; simK, keratometric astigmatism; CMI, corneal morphological irregularity index; MCT, minimum corneal thickness; LogMAR, logarithm of the minimum angle of resolution; D, Diopters; $\mu \mathrm{m}$, micrometers; SD, standard deviation; T0, preoperative evaluation; TI, I month after treatment; T2, 3 months after treatment; T3, I2 months after treatment.

SEQ which was, however, in the expected direction and turned out to be statistically significant in the regression model.

\section{Safety and Complications}

None of the eyes had intraoperative complications. Only one eye $(8.3 \%)$ experienced a graft rejection episode, 5 days after ablation, successfully treated with topical dexamethasone and completely healed after 7 days of therapy. ${ }^{17} \mathrm{~A}$ mild haze (grade 1) was observed in two eyes $(16.7 \%)$. After surgery, all the patients were tolerable to spectacles; moreover, no regression was observed, and further intervention was not needed.

\section{Other Analyses}

A reduction of the correlation between SRAST and SimK was observed from T0 to T3. In particular, a significant regression equation was found at T0 (F 1, 10=37.92, $\mathrm{P}=0.0001)$ with an $\mathrm{R} 2$ of 0.79 and adjusted $\mathrm{R} 2$ of 0.77 , and at $\mathrm{T} 3(\mathrm{~F} 1,10=4.97, \mathrm{P}=0.0498)$ with an $\mathrm{R} 2$ of 0.33 and adjusted R2 of 0.27 . Therefore, as a result of the linear regression analysis, the value of SRAST at T0 was predicted at $77 \%$ : SRAST $=1.66+0.76 * \mathrm{Ksim}$; and at $\mathrm{T} 3$ was predicted at $27 \%$ : SRAST $=1.05+0.34 * \mathrm{~K} \operatorname{sim}$ (Figure 3 ).

\section{Discussion}

The main outcome of this interventional study was to evaluate the long-term efficacy and safety of topographyguided trans-epithelial no-touch ablation to correct for highly irregular astigmatism in post-PK eyes affected by keratoconus. To the best of our knowledge, this is the first prospective study investigating this particular issue with a 12-months follow-up.

The rationale for choosing a topography-guided technique relies on previous studies showing a high rate of retreatment and unpredictability in non-customized refractive surgeries post-PK. In particular, among the latter: arcuate keratotomy was reported to require additional surgical procedures in the $75 \%$ of treated eyes; ${ }^{18}$ noncustomized Laser In Situ Keratomileusis (LASIK) showed to need re-ablations in $10-20 \%$ and non-customized PRK in $5.5-28 \%$ of patients. ${ }^{19-21}$ Likewise, the efficacy and safety of topography-guided photoablations were already highlighted by several studies, with a lower rate of reinterventions. $^{22,23}$

Regarding the topography-guided techniques, both LASIK and PRK have been shown to achieve effective results and no differences have been delineated. ${ }^{24-28}$ Nevertheless, especially in a cohort of transplanted patients, certain concerns about lamellar flap creation and possible irregularities due to the healing process in the LASIK technique have been noted, suggesting a loss of the biomechanical homeostasis of the ocular surface. ${ }^{11,12}$ Similar concerns could arise in PRK ablations requiring corneal epithelial debridement. Performing a topographyguided trans-epithelial no-touch ablation, stromal and epithelial defects as well as haze development could be prevented, and the final refractive result could be more predictable. Moreover, since the corneal epithelium acts as a fluid masking agent, trans-epithelial ablation allows us to eliminate the variability of epithelial thickness due to remodeling and outcomes could be more consistent with the target. ${ }^{11,29,30}$

In our cohort, regarding the efficacy, a significant improvement of UDVA, CDVA, SRAST, simK, SEQ, and CMI $(P<0.0001, \mathrm{P}<0.0001, \mathrm{P}<0.0001, \mathrm{P}<0.0001$, $\mathrm{P}<0.02$ and $\mathrm{P}<0.0001$ respectively) between enrollment (T0) and subsequent follow-ups (T1, T2, and T3), improving tolerance to spectacles and/or CLs was recorded. The significant improvement of UDVA is supported by previous case series or retrospective studies 

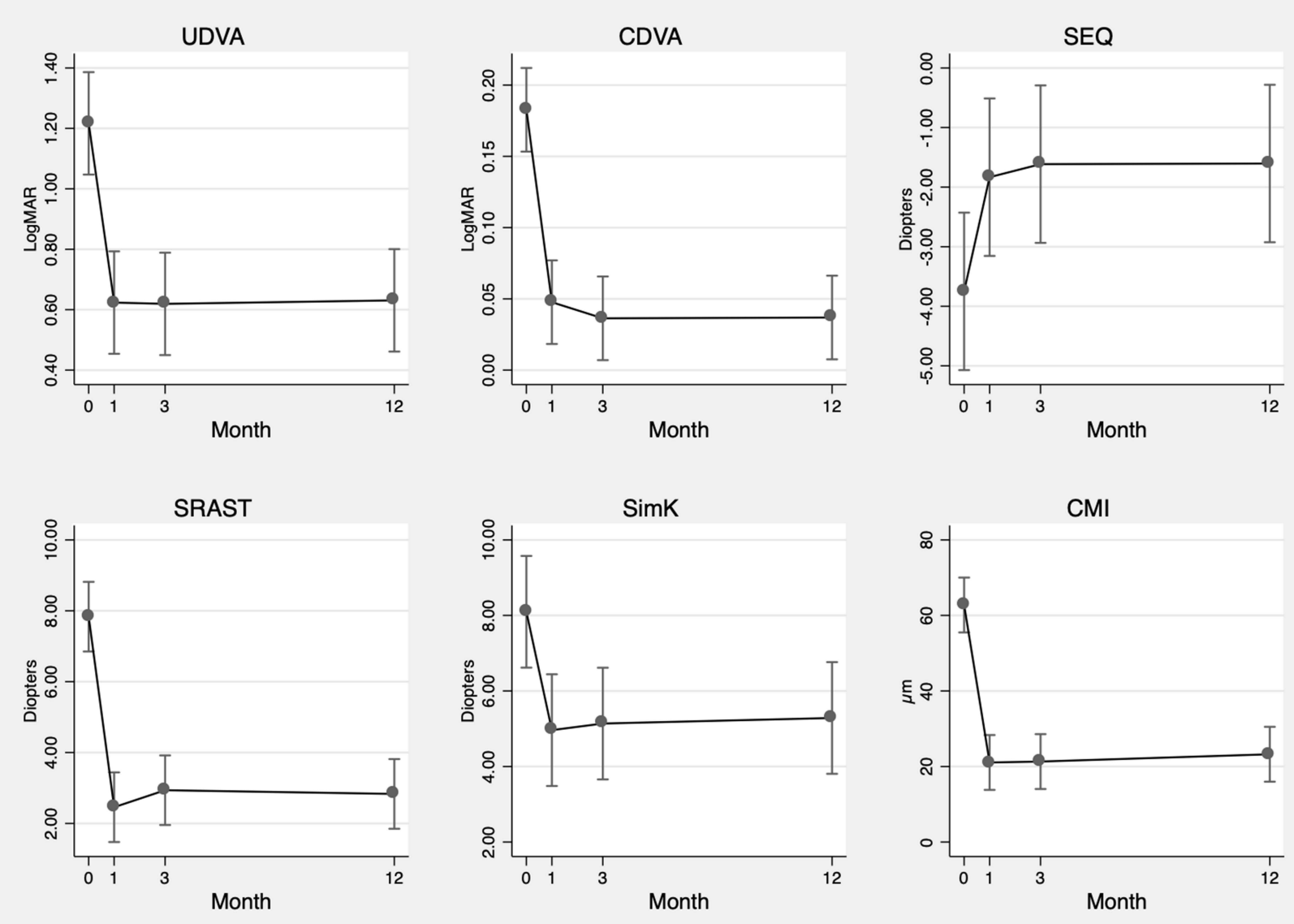

Figure 2 Changes in mean UDVA, CDVA, spherical equivalent (SEQ), refractive astigmatism (SRAST), keratometric astigmatism (SimK) and corneal morphological irregularity index (CMI) over time obtained as marginal effects with confidence intervals (95\%) as resulted from the panel regression analysis.

using the same surgical technique. ${ }^{11,31}$ However, final UDVA values between studies are hardly comparable due to the different refractive characteristics at enrollment, where our patients presented higher values of SRAST, SimK, and SEQ and worse UDVA and CDVA at T0. Consequently, when comparing between studies mean UDVA values at the final follow-up, our cohort obtained a worse visual acuity without the use of spectacles; conversely, when comparing UDVA changes, the observation of a mean improvement of $5.67 \pm 2.93$ lines in our study is consistent with previous literature and in some cases even more conspicuous. ${ }^{14,31}$ In addition, it should be noted that our patients were selected among those who were intolerant to spectacles and/or CLs, and not among those who were likely to reach emmetropia. However, the significant improvement of CDVA is consistent with Sorkin et $\mathrm{al}^{29}$ probably due to highly irregular astigmatism (mean $>6 \mathrm{D}$ ) at enrollment, which could have curtailed the effect of the correction with spectacles or
CLs before intervention. Meanwhile, non-significant improvement of CDVA in other studies could be explained by more regular astigmatism and/or lower astigmatism values, which could have granted a goodquality visual acuity with spectacles or CLs even before PRK. The significant reduction of SRAST, SimK, and SEQ confirms previous literature and enforces evidence of good predictability and efficacy of topography-guided trans-epithelial no-touch surgery. In addition, we investigated the correlation between SRAST and SimK over time, in order to establish the effect of keratometric astigmatism reduction on lens correction needed to obtain the best optical quality and visual acuity. Since no regression occurred in our cohort, we included all treated eyes at different follow-up times; hence, we found a high rate of prediction $(77 \%)$ of SRAST at T0 and a lower rate of prediction of SRAST at T3 (27\%) based on SimK. This loss of correlation could be explained by the average targeted refractive zone diameter that, in our cohort, in 

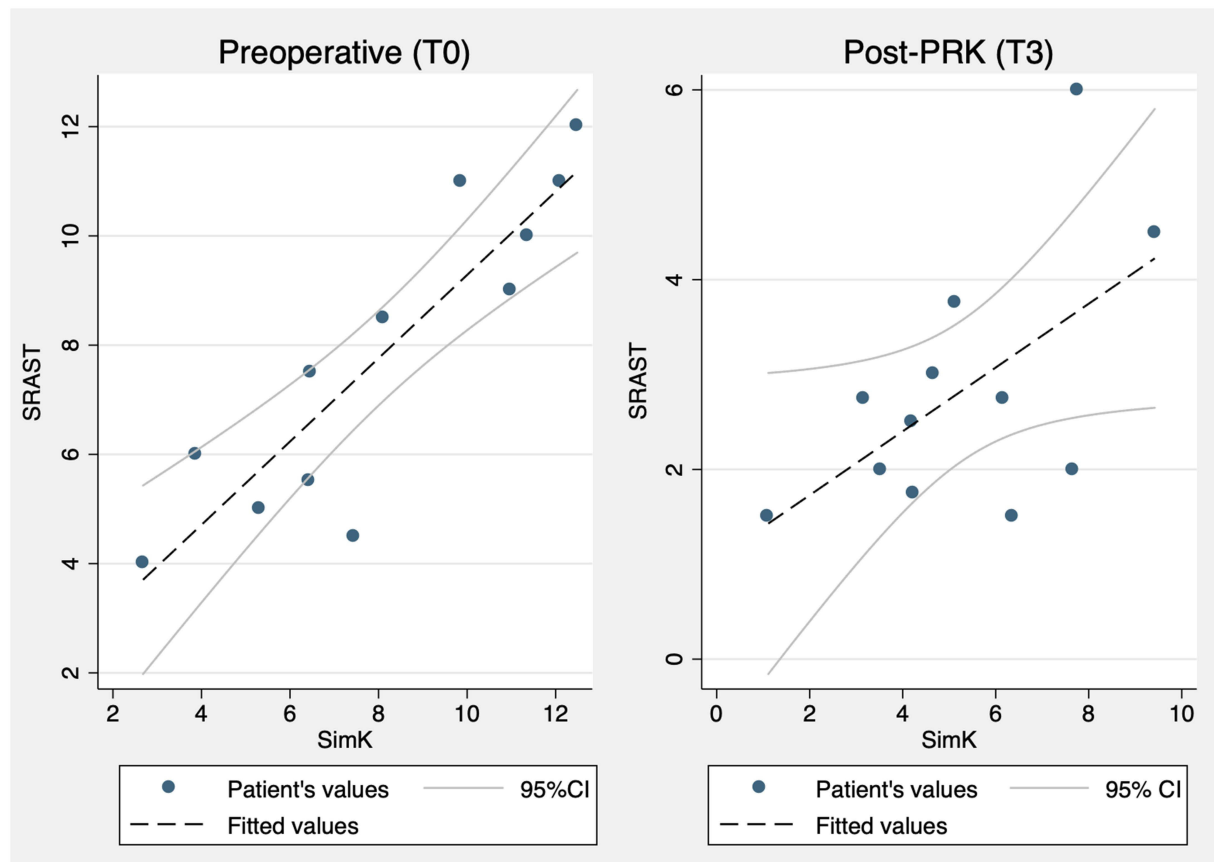

Figure 3 Linear regression model showing relationship between keratometric astigmatism (SimK) and refractive astigmatism (SRAST) before intervention (T0) and at I2 months (T3) after PRK.

order to minimize the invasiveness of the surgical procedure, was equal to $2.89 \pm 0.63 \mathrm{~mm}$ and lower than $3 \mathrm{~mm}$ in more of $58.3 \%$ of treated eyes. Furthermore, the relevant reduction of the CMI within the selected refractive zone could explain the low SRAST values compared to SimK. Therefore, since SimK is referred to $3-\mathrm{mm}$ area of the corneal surface, it may not completely reflect the central corneal refractive astigmatism after surgery. ${ }^{32}$ The CMI is intrinsically related to the quality of vision of the patient and, differently from the HOA, it is independent from the radial distance of the selected measured point. In fact, any cause inducing aberrations above the second order induces an increase of the CMI.

Regarding safety and long-term efficacy, none of our patients developed regression or recorded a loss in visual acuity and none of them needed a re-ablation during follow-up. While safety has already been highlighted by previous literature, the regression rate in our cohort is inconsistent with similar studies, which describe a regression occurring in $10-15 \%$ of treated eyes. ${ }^{33,34}$ This could possibly be explained by a customized connecting zone - the area between the refractive zone and the untouched corneal surface — planned by the CIPTA ${ }^{\circledR} 2$ software. Thereby, granting a constant radial slope to minimize and homogenize the risk of regression in radial direction induced by epithelial regrowth, the observed stability in our cohort may be more solid compared to other PRK techniques. ${ }^{35}$ However, a longer follow-up time could report a certain amount of regression in our cohort.

Finally, the incidence of haze development described in our cohort $(16.7 \%)$ as well as the single graft rejection episode successfully reverted with topic steroids, are consistent with previous literature and they did not influence overall long-term improvement in the involved eyes. ${ }^{33,36,37}$

One strength of our study is to have explored and confirmed the safety and efficacy of topography-guided trans-epithelial no-touch surgery in a cohort of patients, all affected by keratoconus, and all having received the same transplant technique (PK) by the same expert surgeon. With an average of $100 \%$ improvement rate of UDVA, patients were able to ameliorate their autonomy in activities of daily living even without the use of spectacles or CL. In parallel, we were able to reduce residual refractive error (SEQ and SRAST) in spectacles prescription - thus improving tolerability - regardless of the SimK values; this suggests a role of customized ablation in reducing aberrations and corneal morphological irregularities specifically in the selected refractive zone. 
Furthermore, as far as we know, this is the first prospective study involving the CIPTA ${ }^{\circledR} 2$ software in transplanted eyes using CMI as a specific parameter to evaluate corneal aberrations with a 12-month follow-up. Among the shortcomings of our study, despite promising and statistically significant results, possible bias deriving from a relatively small sample size - due to the rarity of the disease and condition - and from a short follow-up time should be disclosed. In addition, a control group performing a PRK with epithelial debridement or with the use of mitomycin $\mathrm{C}$ or even a LASIK ablation could have strengthened our findings.

\section{Conclusions}

Our study demonstrated effectiveness, safety, and longterm stability of the one-step topography-guided transepithelial no-touch surgery planned by the CIPTA ${ }^{\circledR} 2$ software in eyes with post-PK highly irregular astigmatism. In addition, the increase of UDVA and CDVA and the reduction of SRAST went along with the reduction of CMI, reducing residual aberrations.

\section{Funding}

This research did not receive any specific grant from funding agencies in the public, commercial, or not-forprofit sectors.

\section{Disclosure}

The authors report no conflicts of interest in this work.

\section{References}

1. Alió JL, Abdou AA, Abdelghany AA, Zein G. Refractive surgery following corneal graft. Curr Opin Ophthalmol. 2015;26(4):278-287. doi:10.1097/ICU.0000000000000161

2. Fares U, Sarhan ARS, Dua HS. Management of post-keratoplasty astigmatism. J Cataract Refract Surg. 2012;38(11):2029-2039. doi:10.1016/j.jcrs.2012.09.002

3. Bilgihan K, Özdek SC, Akata F, Hasanreisoğlu B. Photorefractive keratectomy for post-penetrating keratoplasty myopia and astigmatism. J Cataract Refract Surg. 2000;26(11):1590-1595. doi:10.1016/S0886-3350(00)00692-1

4. E Silva FB, Hazarbassanov RM, Martines E, Güell JL, Hofling-Lima AL. Visual outcomes and aberrometric changes with topography-guided photorefractive keratectomy treatment of irregular astigmatism after penetrating keratoplasty. Cornea. 2018;37:283-289. doi:10.1097/ICO.0000000000001474

5. Severinsky B, Behrman S, Frucht-Pery J, Solomon A. Scleral contact lenses for visual rehabilitation after penetrating keratoplasty: long term outcomes. Cont Lens Anterior Eye. 2014;37(3):196-202. doi:10.1016/ j.clae.2013.11.001

6. Szczotka LB, Lindsay RG. Contact lens fitting following corneal graft surgery. Clin Expl Optom. 2003;86(4):244-249. doi:10.1111/j.14440938.2003.tb03113.x
7. Alipour F, Khaheshi S, Soleimanzadeh M, Heidarzadeh S, Heydarzadeh S. Contact lens-related complications: a review. J Ophthalmic Vis Res. 2017;12(2):193-204. doi:10.4103/jovr. jovr_159_16

8. Arshad $\bar{M}$, Carnt N, Tan J, Stapleton F. Compliance behaviour change in contact lens wearers: a randomised controlled trial. Eye. 2020. doi:10.1038/s41433-020-1015-9

9. Ho SK, Andaya L, Weissman BA. Complexity of contact lens fitting following penetrating keratoplasty. Int Contact Lens Clin. 1999;26 (6):163-167. doi:10.1016/S0892-8967(01)00041-4

10. Huang PYC, Huang PT, Astle WF, et al. Laser-assisted subepithelial keratectomy and photorefractive keratectomy for post-penetrating keratoplasty myopia and astigmatism in adults. $J$ Cataract Refract Surg. 2011;37(2):335-340. doi:10.1016/j.jcrs.2010.08.039

11. Pedrotti E, Sbabo A, Marchini G. Customized transepithelial photorefractive keratectomy for iatrogenic ametropia after penetrating or deep lamellar keratoplasty. J Cataract Refract Surg. 2006;32 (8):1288-1291. doi:10.1016/j.jcrs.2006.03.032

12. Solomon R, Donnenfeld ED, Perry HD. Photorefractive keratectomy with mitomycin $\mathrm{C}$ for the management of a LASIK flap complication following a penetrating keratoplasty. Cornea. 2004;23(4):403-405. doi:10.1097/00003226-200405000-00018

13. Spadea L, Mosca L, Balestrazzi E. Effectiveness of LASIK to correct refractive error after penetrating keratoplasty. Ophthalmic Surg Lasers. 2000;31(2):111-120. doi:10.3928/1542-8877-20000301-07

14. Alessio G, Boscia F, La Tegola MG, Sborgia C. Topography-driven excimer laser for the retreatment of decentralized myopic photorefractive keratectomy. Ophthalmology. 2001;108(9):1695-1703. doi:10.1016/S0161-6420(01)00706-0

15. Kovoor TA, Mohamed E, Cavanagh HD, Bowman RW. Outcomes of LASIK and PRK in previous penetrating corneal transplant recipients. Eye Contact Lens. 2009;35(5):242-245. doi:10.1097/ ICL.0b013e3181b401f9

16. Roh HC, Chuck RS, Lee JK, Park CY. The effect of corneal irregularity on astigmatism measurement by automated versus ray tracing keratometry. Medicine. 2015;94:13. doi:10.1097/MD.0000000 000000677

17. Spadea L, Giannico MI, Armentano M, Alisi L, Pistella S. Acute corneal graft rejection following photorefractive keratectomy for post-penetrating keratoplasty high astigmatism. Int $J$ Ophthalmol. 2021;14(3):30-31. doi:10.18240/ijo.2021.03

18. Bayramlar H, Karadag R, Cakici O, Ozsoy I. Arcuate keratotomy on post-keratoplasty astigmatism is unpredictable and frequently needs repeat procedures to increase its success rate. $\mathrm{Br} J$ Ophthalmol. 2016;100(6):757-761. doi:10.1136/bjophthalmol-2015-306738

19. Gartry DS, Larkin DF, Hill AR, Ficker LA, Steele AD. Retreatment for significant regression after excimer laser photorefractive keratectomy: a prospective, randomized, masked trial. Ophthalmology. 1998;105(1):131-141. doi:10.1016/S0161-6420(98)91715-8

20. Hersh PS, Fry KL, Bishop DS. Incidence and associations of retreatment after LASIK. Ophthalmology. 2003;110(4):748-754. doi:10.1016/S0161-6420(02)01981-4

21. Gibralter R, Trokel SL. Correction of irregular astigmatism with the excimer laser. Ophthalmology. 1994;101(7):1310-1315. doi:10.1016/ S0161-6420(94)31174-2

22. Tamayo Fernandez GE, Serrano MG. Early clinical experience using custom excimer laser ablations to treat irregular astigmatism. J Cataract Refract Surg. 2000;26(10):1442-1450. doi:10.1016/ S0886-3350(00)00565-4

23. Hjortdal JO, Ehlers N. Treatment of post-keratoplasty astigmatism by topography supported customized laser ablation. Acta Ophthalmol Scand. 2001;79(4):376-380. doi:10.1034/j.1600-0420.2001.079004376.x

24. de Rosa G, Boccia R, Santamaria C, Fabbozzi L, de Rosa L, Lanza M. Customized photorefractive keratectomy to correct high ametropia after penetrating keratoplasty: a pilot study. J Optom. 2015;8(3):174-179. doi:10.1016/j.optom.2013.12.002 
25. Barraquer C, Rodriguez-Barraquer T. Five-year results of laser in-situ keratomileusis (LASIK) after penetrating keratoplasty. Cornea. 2004;23(3):243-248. doi:10.1097/00003226-200404000-00005

26. Dausch D, Schröder E, Dausch S. Topography-controlled excimer laser photorefractive keratectomy. J Refract Surg. 2000;16(1):13-22. doi:10.3928/1081-597X-20000101-03

27. Laíns I, Rosa AM, Guerra M, et al. Irregular astigmatism after corneal transplantation - efficacy and safety of topography-guided treatment. Cornea. 2016;35(1):30-36. doi:10.1097/ICO.00000000 00000647

28. Spadea L, Mosca L. Topographically guided LASIK. Ophthalmology. 2006;113(7):1251-e1. PMID: 16815418. doi:10.1016/j. ophtha.2006.03.004

29. Sorkin N, Einan-Lifshitz A, Abelson S, et al. Stepwise guided photorefractive keratectomy in treatment of irregular astigmatism after penetrating keratoplasty and deep anterior lamellar keratoplasty. Cornea. 2017;36(11):1308-1315. doi:10.1097/ICO.000000000 0001359

30. Spadea L, Giammaria D, Trabucco P. Corneal wound healing after laser vision correction. Br J Ophthalmol. 2016;100(1):28-33. PMID: 26405102. doi:10.1136/bjophthalmol-2015-306770

31. Bizrah M, Lin DTC, Babili A, Wirth MA, Arba-Mosquera S, Holland SP. Topography-guided photorefractive keratectomy for postkeratoplasty astigmatism: long-term outcomes. Cornea. 2021;40 (1):78-87. doi:10.1097/ICO.0000000000002403
32. Teus MA, Arruabarrena C, Hernández-Verdejo JL, Sales-Sanz A, Sales-Sanz M. Correlation between keratometric and refractive astigmatism in pseudophakic eyes. J Cataract Refract Surg. 2010;36 (10):1671-1675. doi:10.1016/j.jcrs.2010.05.010

33. Kuo IC, Lee SM, Hwang DG. Late-onset corneal haze and myopic regression after photorefractive keratectomy (PRK). Cornea. 2004;23 (4):350-355. doi:10.1097/00003226-200405000-00007

34. Moshirfar M, Anderson E, Hsu M, Armenia JM, Mifflin MD. Comparing the rate of regression after conductive keratoplasty with or without prior laser-assisted in situ keratomileusis or photorefractive keratectomy. Middle East Afr J Ophthalmol. 2012;19 (4):377-381. doi:10.4103/0974-9233.102743

35. Mulè G, Chen S, Zhang J, et al. Central corneal regularization (CCR): an alternative approach in keratoconus treatment. Eye Vis. 2019;6(1):1-7. doi:10.1186/s40662-019-0165-y

36. Spadea L, Giovannetti F. Main complications of photorefractive keratectomy and their management. Clin Ophthalmol. 2019;13:2305-2315. doi:10.2147/OPTH.S233125

37. Pokroy R, Mimouni M, Sela T, Munzer G, Kaiserman L. Predictors of myopic photorefractive keratectomy retreatment. J Cataract Refract Surg. 2017;43(6):825-832. doi:10.1016/j.jcrs.2017.06.001
Therapeutics and Clinical Risk Management

\section{Publish your work in this journal}

Therapeutics and Clinical Risk Management is an international, peerreviewed journal of clinical therapeutics and risk management, focusing on concise rapid reporting of clinical studies in all therapeutic areas, outcomes, safety, and programs for the effective, safe, and sustained use of medicines. This journal is indexed on PubMed Central, CAS,
Dovepress

EMBase, Scopus and the Elsevier Bibliographic databases. The manuscript management system is completely online and includes a very quick and fair peer-review system, which is all easy to use. Visit http://www.dovepress.com/testimonials.php to read real quotes from published authors. 